\title{
Current Practices Related to Feeding Preterm Neonates with Expressed Breast Milk: A Pilot Project
}

\author{
Daljeet kaur ${ }^{1}$, Avinash kaur Rana ${ }^{1 *}$, Geetanjli kalyan ${ }^{2}$ and Praveen Kumar ${ }^{3}$ \\ ${ }^{1}$ National Institute of Nursing Education (NINE), Postgraduate Institute of Medical Education \& Research, India \\ ${ }^{2}$ Clinical instructor, National Institute of Nursing Education (NINE), Postgraduate Institute of Medical Education \& Research, India
}

${ }^{3}$ Department of Paediatrics, Postgraduate Institute of Medical Education \& Research, India

*Corresponding author: Avinash kaur Rana, National Institute of Nursing Education (NINE), Postgraduate Institute of Medical Education \& Research, India

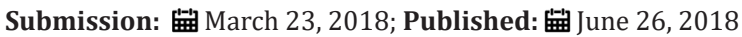

\begin{abstract}
A pilot project was conducted to assess current practices related to feeding pretermneonates with expressed breast milk. The present project was conducted with the objectives to assess current practices related to feeding preterm neonates with expressed breast milk admitted in tertiary level hospital, North India. Practices related to expressed breast milk feeding in preterm neonates was assessed in 4 steps. In step one of Information and current practices related to expression of breast milk among mothers was assessed. Practices in neonatal unit revealed that $92 \%$ of mothers had knowledge about feeding schedule of babies. In context to infection control practices $96 \%$ mothers washed hands, $92 \%$ wore gown, and all mothers $(100 \%)$ used boiled utensils. Eighty two percent mothers expressed milk at least eight times in 24 hour including once during night. Feeding detail of preterm neonates revealed that amount of expressed breast milk fed was very less as compare to enteral feed calculated per day.
\end{abstract}

To fulfill the requirement formula feed was given. In step two audits for expressed breast milk feeding was done. The pre-assessment audit of labour room showed that only three percent of mothers expressed milk with in 1 hour of delivery and out of those who expressed milk after 1 hour $20 \%$ of mothers were assisted by health professionals at first time expression after delivery. $60 \%$ mothers were educated by PHN and 30\% by nursing staff in labour room.

Step three feeding details of preterm neonates were assessed. It revealed that maximum amount $(102.1 \mathrm{ml} / \mathrm{kg})$ of expressed breast milk was fed on day eight and minimum $(3.9 \mathrm{ml} / \mathrm{kg})$ on day 2 of life. Data showed that breast milk was not sufficient to full fill the requirement of baby throughout 10 days and formula milk was added to meet the requirement. Pilot project concluded that mothers of preterm neonates require health education on expression of breast milk, amount of expressed breast milk feeding is very less as compare to enteral feed calculated.

Keywords: Current practices; Expressed breast milk feeding; Preterm neonates

\section{Introduction}

The premature babies face number of problems due to their immature physiology. Hypothermia, respiratory distress syndrome, neonatal jaundice, infection, hypoglycemia and necrotizing enteritis etc [1]. Breast milk produced by mammary gland of human female, a primary source of nutrition for new borns before they are able to eat and digest other foods. Exclusive breast feeding should be given for first six month of life after that supplemented breastfeeding is recommended along with complementary feeding until 2years of age [2]. If we talk about composition of human milk it contains $8 \%$ to $9 \%$ protein, $4.5 \%$ fat, $7.1 \%$ carbohydrates mainly lactose, $0.2 \%$ minerals [3] and also IgA which is high from day $10^{\text {th }}$ up to 7.5 month post partum [4]. Concentration of nutrients varies with term and preterm milk. Preterm milk contains higher concentration of nitrogen protein, sodium, chloride, magnesium and iron than term milk. Components like non protein nitrogen, volume, solids, total calories, lactose, fat, fatty acid, potassium and calcium are same in both type of milk (preterm and term milk) [5,6].

Preterm human milk is much suitable than term human milk, for the premature babies. In case of preterm neonates it is big challenge to provide adequate nutrition to infants due to several problems such as immaturity like bowel function, inability to suck and swallow, high risk of necrotizing enterocolitis (NEC), respiratory distress syndrome, patent ductus arteriosus [7] in addition to this medical interventions such as umbilical vessel catheters, exchange transfusion, indomethacin therapy which increases the problems of these babies (Table 1). Premature babies who stayed in NICU, breast milk reduces the risk of short-and long-term morbidities such as enteral feed intolerance, nosocomial infection; necrotizing 
enterocolitis (NEC), chronic lung disease (CLD), retinopathy of prematurity (ROP), developmental and neurocognitive delay, and re hospitalization after NICU discharge [8-11], breast milk contains immunoglobulins, phagocytes and enzymes such as lysozymes, antibodies and vitamin $\mathrm{K}$ which protect infant from infection [12].

Table 1: Daily information and practices related to expression of breast milk during feeding sessions among mothers.

\begin{tabular}{|c|c|}
\hline Item & Yes n $(\%)$ \\
\hline \multicolumn{2}{|l|}{ Information Related to } \\
\hline Quantity of milk requirement per day of baby & $12(48)$ \\
\hline Technique of expression & $10(40)$ \\
\hline Feeding schedule & $23(92)$ \\
\hline \multicolumn{2}{|c|}{ Infection Control Practices } \\
\hline Hand washed & $24(96)$ \\
\hline Gown changed & $23(92)$ \\
\hline Breast cleaned before expression & $21(84)$ \\
\hline Used boiled utensils & $25(100)$ \\
\hline Maintained sterility of utensils throughout procedure & $13(52)$ \\
\hline \multicolumn{2}{|c|}{ Frequency of Expression } \\
\hline At least 8 times in 24 hour including once during night & $20(80)$ \\
\hline \multicolumn{2}{|l|}{ Timing of Expression } \\
\hline No gaps longer than 4 hours(day times) & $20(80)$ \\
\hline No gaps longer than 6 hours(night time) & $20(80)$ \\
\hline \multicolumn{2}{|c|}{ Stimulating Milk Ejection } \\
\hline Uses relaxation.(e.g. breathing exercises) & --- \\
\hline Skin to skin contact & --- \\
\hline Expressing milk near baby(closeness) & $02(08)$ \\
\hline \multicolumn{2}{|l|}{ Procedure } \\
\hline \multicolumn{2}{|l|}{ Practices breast exercises } \\
\hline Circular & $14(56)$ \\
\hline Shaking & $02(08)$ \\
\hline Striking & $02(08)$ \\
\hline Squeezing & $25(100)$ \\
\hline \multicolumn{2}{|l|}{ Breast Condition } \\
\hline Feels breast fullness prior to expression & $22(88)$ \\
\hline Softens following expression & $07(28)$ \\
\hline No red areas or nipple trauma & $18(72)$ \\
\hline \multicolumn{2}{|l|}{ Milk Volume } \\
\hline Amount of milk expressed as per the requirement of baby & $12(48)$ \\
\hline
\end{tabular}

\section{Material and Methods}

Current practices regarding feeding preterm neonates with expressed milk was assessed in neonatal unit, LR, maternity and
CLR extension, tertiary level hospital, North India. Project was completed in three phases. Data was collected in quantitative form (Table 2). 
Table 2: Audit for expressed breast milk feeding practices in labour room $\mathrm{N}=30$.

\begin{tabular}{|c|c|}
\hline Item & Yes n (\%) \\
\hline Expression of milk within 1 hour of delivery & $1(3.3)$ \\
\hline Any health professional assisted in expression of milk? & $6(20)$ \\
\hline $1^{\text {st }}$ health education on expressed breast milk in \\
\hline Labour Room \\
\hline PHN & $18(60)$ \\
\hline Nursing staff & $09(30)$ \\
\hline
\end{tabular}

A. Step 1: Assessment of Information and current practices related to expression of breast milk among mothers

Sample population was mothers of preterm neonates admitted in neonatal unit which were selected by purposive sampling technique. Sample size was 25 breast milk expression sessions. Tool was comprised of items related to daily Information and practices related to expression of breast milk during feeding session among mothers Data was collected by using observational check list. Observations were made in neonatal unit when mothers express breast milk. Information about study was given to mothers

Table 3 Feeding detail of preterm neonates $\mathrm{N}=15$. and purpose of observation was also explained to mothers. Total 25 breast milk expression sessions were observed and questions were asked from mothers on daily basis where some mothers have been interviewed more than once.

\section{B. Step 2: Audit for expressed breast milk feeding}

Audit was done in CLR where mothers admitted after delivery. Sample population was mothers of preterm neonates admitted in neonatal unit and selected by purposive sampling technique. Data was collected by filling questionnaire by asking questions to mothers after delivery. Information about study was given to mothers. Purpose of audit was to know about the practices of expressed breast milk feeding after delivery.

\section{Step 3: Assessment of feeding details of preterm neonates}

Feeding details of preterm neonates were assessed in Neonatal unit. Sample was selected by total enumeration sampling technique. Sample population waspreterm neonates admitted in neonatal unit. Fifteen preterm neonates were included was included on the basis of inclusion criteria.Data was collected from record i.e. Dutta Chart. Feeding detail of 15 preterm neonates was noted on feeding details proforma for ten days (Table 3 ).

\begin{tabular}{|c|c|c|c|c|c|c|}
\hline \multirow{2}{*}{ Day of Life } & Weight (kg) & $\begin{array}{c}\text { Enteral Feed } \\
\text { Prescribed (ml/ } \\
\mathbf{k g})\end{array}$ & $\begin{array}{c}\text { Expressed Breast } \\
\text { Milk Fed (ml/kg) }\end{array}$ & $\begin{array}{c}\text { Formula Milk Fed } \\
\text { (ml/kg) }\end{array}$ & $\begin{array}{c}\text { Expressed Breast } \\
\text { Milk as \% of total }\end{array}$ & $\begin{array}{c}\text { Formula Milk as } \\
\% \text { of Total }\end{array}$ \\
\cline { 2 - 7 } & Median (IQR) & Median (IQR) & Median (IQR) & Median (IQR) & Median (IQR) & Median (IQR) \\
\hline Day 1 & $1.09(.96-1.10)$ & $021.5(15-48.8)$ & $05.7(.00-16.9)$ & $11.8(3.6-23.9)$ & $12.9(0-49.7)$ & $87.1(0-100)$ \\
\hline Day 2 & $1.05(.96-1.19)$ & $040.0(32.2-50.4)$ & $03.9(.00-24.3)$ & $24.0(.0-50.4)$ & $16.7(0-57.1)$ & $52.9(0-95.9)$ \\
\hline Day3 & $1.01(.91-1.14)$ & $071.2(47.4-97.2)$ & $13.1(3.6-36.8)$ & $55.5(0-82.0)$ & $18.1(0-100)$ & $29.1(0-85.1)$ \\
\hline Day4 & $1.00(.84-1.11)$ & $098.4(57-125.2)$ & $53.3(2.8-76.1)$ & $34.2(0-75.8)$ & $54.1(7.4-100)$ & $26.4(0-75)$ \\
\hline Day5 & $1.02(.83-1.11)$ & $125.0(36-157)$ & $36.0(23-131.5)$ & $08.8(0-73.8)$ & $91.6(16.5-100)$ & $08.4(0-61.1)$ \\
\hline Day6 & $1.03(.88-1.13)$ & $140.0(67-174.7)$ & $67.0(67-148.5)$ & $00(0-81.6)$ & $84.2(16.6-100)$ & $00(0-58.4)$ \\
\hline Day7 & $1.02(.92-1.14)$ & $144.0(80-176.5)$ & $80.0(26.3-148)$ & $09.3(0-66)$ & $86.1(14.1-100)$ & $08.6(0-46)$ \\
\hline Day8 & $1.01(.90-1.14)$ & $143.0(45.7-184.6)$ & $102.1(22.8-150)$ & $03.6(0-38)$ & $85.6(32.8-100)$ & $14.2(0-67.2)$ \\
\hline Day9 & $.992(.86-1.13)$ & $139.8(62.7-177.9)$ & $84.0(26.8-162)$ & $10.7(0-62.7)$ & $91.6(31.1-100)$ & $08.4(0-61.5)$ \\
\hline Day10 & $.985(.86-1.13)$ & $170.4(40.1-178.3)$ & $73.1(7.1-178.3)$ & $0(0-35.2)$ & $84.8(22-100)$ & $08.3(0-57.8)$ \\
\hline
\end{tabular}

\section{Result}

\section{Daily information and practices related to expression of breast milk during feeding sessions among mothers}

Results of daily information and practices related to expression of breast milk during feeding sessions among mothers revealed that most of mothers (92\%) had information related to feeding schedule of baby but only $48 \%$ were informed about quantity of milk required per day and $40 \%$ knew about technique of expression of milk. In context to infection control practices $96 \%$ of mothers performed hand washing, $92 \%$ changed gown, 100\% used boiled utensils, $84 \%$ of mothers cleaned breasts before expression and only half $(52 \%)$ of mothers maintained sterility of utensils throughout procedure. About frequency and timing of milk expression $80 \%$ of mothers express at least 8 times in 24 hour including once during night with no gaps longer than 4hours (day times) and 6hours (night time). None of them have used the milk ejection stimulating techniques. If we talk about breast exercises mothers had very less knowledge about breast exercises. Only $52 \%$ of mothers practiced circular exercise and slightly more than $1 / 4$ (28\%) of mothers breasts soften following expression. Incidence of redness and nipple trauma were $72 \%$. Only $48 \%$ mothers were able to express the amount of milk as per the requirement of baby (Figure 1). 


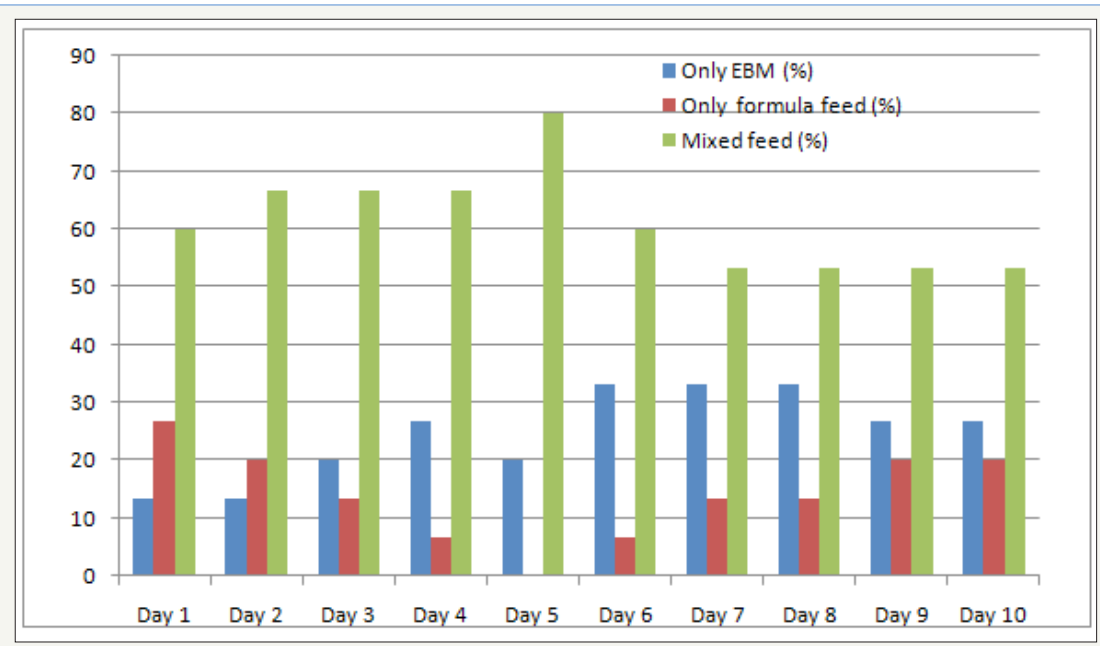

Figure 1: Babies fed with EBM, formula, mixed feed.

\section{Audit for expressed breast milk feeding practices}

Results of audit performed in labor room for expressed breast milk feeding practices showed that $3.3 \%$ of mothers expressed breast milk within 1 hour of delivery. Out of those who expressed milk after 1 hour of delivery $20 \%$ of mothers were assisted by health professional at first time milk expression after delivery. Health education was given by PHN to majority of mothers (60\%) and $30 \%$ were educated by nursing staff and remaining $10 \%$ were not educated in labor room.

\section{Feeding detail of preterm neonates}

Feeding detail of preterm neonates revealed that amount of expressed breast milk fed was very less as compare to enteral feed calculated. Amount of enteral feed prescribed had increase with day of life but amount of expressed breast milk fed had not increase accordingly. Maximum amount $(102.1 \mathrm{ml} / \mathrm{kg})$ of expressed breast milk was fed on day eight and minimum $(3.9 \mathrm{ml} / \mathrm{kg})$ on day 2 of life. Data showed that breast milk was not sufficient to full fill the requirement of baby throughout 10 days and formula milk was added to meet the requirement. In context to percent of expressed breast milk out of total, minimum $12.9 \%$ was on day 1 of life and maximum $91.6 \%$ was on day 5 and 9 of life. Percent of formula milk out of total, was maximum (87.1\%) on day 1 of life and minimum $(8.3 \%)$ on day 10 of life.

\section{Number of babies fed with EBM, formula, mixed feed}

Expressed breast milk was given to very less number of babies $(13.3 \%)$ at day 1, 2 of life and to maximum no (33.3\%) on 6-8 days of life. Formula feed was given to maximum number of babies (26.7\%) on day 1 and none of them were fed with formula feed on day 5. Mixed feed was given to majority of babies as compared to EBM and formula feed. In general maximum number of babies was fed with mixed feed on day 5 and minimum on 7-10 days of life.

\section{Discussion}

Breast milk is superior to all other feeds for new born. It contains all the nutrients the infant needs for proper growth and development. Breast milk also contain some non-nutritional component like antimicrobial factors, digestive enzymes, hormones and growth factors etc. breast milk can be divided in to three types colostrum (1-7days), Transitional milk (8-20days), Mature milk (after 20days) which are different in composition. Preterm and term milk are also different in its composition. According to Dawodu AH et al. [2] the preterm mothers' milk contained higher concentrations of protein, fat and minerals and lower concentrations of lactose than term mother's milk [13]. The premature baby faces a number of problems. Due to their immature physiology i.e. Hypothermia, respiratory distress syndrome, neonatal jaundice, infection, Hypoglycemia and necrotizing enteritis etc $[14,15]$. Hylander MA [15] in 'Human milk feedings and retinopathy of prematurity among very low birth weight infants' concluded that incidence and severity of retinopathy of prematurity are significantly low in those who were exclusively breastfed or whose diet consisted of at least $80 \%$ of human milk [16]. According to another studies the incidence of any infection, including necrotizing enterocolitis, sepsis and meningitis, is significantly lower in very low birth weight (VLBW) infants fed human milk, when compared to those fed only artificial milk $[17,18]$.

Mothers of preterm neonates who are admitted in neonatal units should be encouraged for expression of milk. Benefits of breast milk should be explained to the mother. Techniques should also be discussed with mothers. Counsel the mother for breast feeding. Nuriye BD [18] 'The effect of counselling provided on the second postpartum day through home visits on breastfeeding success in turkey: randomized, controlled trial' said that the rate of babies fed only with breast milk by the women who were counsel during the last 24 hours was higher than those in the control group [19]. According to present study out of those who expressed milk after 1 hour of delivery $20 \%$ of mothers were assisted by health professional at first time milk expression after delivery. Health education was given by PHN to majority of mothers $(60 \%)$ and $30 \%$ were educated by nursing staff and remaining $10 \%$ were not educated in labor room. Mother's anxiety and concern about newborn also affect the let down milk [20]. 
Psychological support should be given to mother. If possible time should be given to mother to stay with baby for some time. Encourage her to keep photo of baby in front and think about baby at time of expression. Present study revealed that only $8 \%$ of mothers express milk near baby. Provide privacy to mothers at the time of expression because according to one study the majority of the mothers (55\%) were most comfortable pumping in their own homes because of the increased privacy [21]. Present study revealed that $56 \%$ of mothers did circular exercise whereas only $8 \%$ did striking and shaking. Its expression should always be preceded by careful hand washing. Infection control practices in present study showed that $96 \%$ of mothers performed hand washing [21]. Milk production is directly associated with the frequency of expression. Among mothers of non breast fed preterm infants who express milk four or more times a day, the volume of milk obtained is significantly larger than those who express milk three times or less a day [20]. Pilot project concluded that mothers of preterm neonates require health education on expression of breast milk, amount of expressed breast milk feeding is very less as compare to enteral feed calculated and number of barriers and suggested facilitators were reported by nursing staff and mothers.

\section{References}

1. Evans k (2016) Cardiovascular transition of the extremely premature infant and challenges to maintain hemodynamic stability. International Journal of Public Health and Clinical Sciences 30(1): 68-72.

2. Dawodu AH, Osibanjo O, Damole IO (1990) Nutrient composition of milk produced by mothers of preterm infants in Nigeria. East Afr Med J 67(12): 873-877.

3. Rechtman DJ, Ferry B, Lee ML, Chapel H (2002) Immunoglobulin A ( $\operatorname{IgA}$ ) content of human breast milk over time. International Journal of Infectious Diseases 6(2): S58.

4. Hill PD, Aldag JC, Chatterton RT, Zinaman M (2005) Comparison of milk output between mothers of preterm and term infants: The first 6 weeks after birth. J Hum Lact 21(1): 22-30.

5. James AL, Lemuel M, Hall D, Michael S (1982) Differences in the composition of preterm and term human milk during early lactation. Pediatric Research 16(2): 113-117.

6. Basavanthappa BT (2005) Pediatric/ child health nursing. (1 $1^{\text {st }}$ edn), Ahuja Publishing House, New Delhi, India, pp. 114- 222.

7. Lucas A, Cole TJ (1990) Breast milk and neonatal necrotizing enterocolitis. The Lancet 336(8730-8731): 1519-1523.
8. Lucas A, Morley R, Cole TJ, Lister G, Leeson P C (1992) Breast milk and subsequent intelligence quotient in children born preterm. Lancet 339(8788): 261-264

9. Bier JA, Oliver T, Ferguson AE, Vohr BR (2002) Human milk improves cognitive and motor development of premature infants during infancy. J Hum Lact 18(4): 361-367.

10. Obrein R (2008) Breast milk helps mental development in premature babies. American Chronicle, USA.

11. Narayanan I, Prakash K, Gujral VV (1981) The value of human milk in the prevention of infections in the high-risk low-birth-weight infant. J Pediatr 99(3): 496-498.

12. Dawodu AH, Osibanjo NO, Damole IO (1990) Nutrient composition of milk produced by mothers of preterm infants in Nigeria 67(12): 873877.

13. Wood NS, Marlow N, Costeloe K, Gibson AT, Wilkinson AR (2000) Neurologic and developmental disability after extremely preterm birth. N Engl J Med 343(6): 378-384.

14. Effer SB, Moutquin JM, Farine D, Saigal S, Nimrod C (2002) Neonatal survival rates in 860 singleton live births at 24 and 25 weeks gestational age. A Canadian multicenter study. Br J Obstet Gynaecol 109(7):740-745.

15. Hylander MA, Strobino DM, Dhanireddy R (1996) Human milk feedings and retinopathy of prematurity among very low birth weight infants. Pediatr Res 37: 214

16. Leila Rangel da Silva, Maria EmanueleIzidro de Souza Elles, Maíra Domingues Bernardes Silva, Inês Maria Meneses dos Santos, Kleyde Ventura de Souza, et al. (2012) Social factors that influence breastfeeding of premature newborns: descriptive study. Online brazlln journal of nursing 11(1): 40-51.

17. Lucas A, Cole TJ (1990) Breastmilk and neonatal necrotising enterocolitis. Lancet 336(8730): 1519-1523.

18. Nuriye BD (2012) The effect of counselling provided on the second post partum day through home visits on breastfeeding success in turkey: randomized, controlled trial. Journal of Nursing Education and Practice 2(1): 91-100.

19. Jones E, Dimmock AS, Spencer SA (2001) A randomised controlled trial to compare methods of milk expression after preterm delivery. Arch Dis Child Fetal Neonatal Ed 85(2): F91-F95.

20. Dowling DA, Blatz MA, Graham G (2012) Mothers' experiences expressing breast milk for their preterm infants: does NICU design make a difference. Adv Neonatal Care 12(6): 377-384.

21. De Carvalho M, Anderson DM, Giangreco A, Pitard WB (1985) Frequency of milk expression and milk production by mothers of nonnursing premature neonates. AJDC 139(5): 483-485.
Creative Commons Attribution 4.0 International License

For possible submissions Click Here

\section{Submit Article}

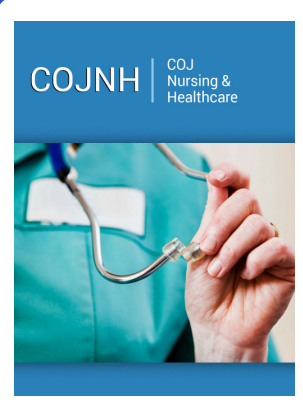

COJ Nursing \& Healthcare

\section{Benefits of Publishing with us}

- High-level peer review and editorial services

- Freely accessible online immediately upon publication

- Authors retain the copyright to their work

- Licensing it under a Creative Commons license

- Visibility through different online platforms 